\title{
PENGGUNAAN BAMBU PETUNG SEBAGAI ALTERNATIF MATERIAL KONSTRUKSI DINDING PENAHAN GALIAN PADA KONDISI TANAH NON KOHESIF
}

\author{
Kurniadi Wahyudianto ${ }^{1}$, Yusep Muslih Purwana ${ }^{2}$, dan Niken Silmi Surjandari ${ }^{3}$ \\ ${ }^{1}$ Program Studi Magister Teknik Sipil Universitas Sebelas Maret Surakarta \\ adhujugaa@gmail.com \\ 2,3 Jurusan Teknik Sipil Fakultas Teknik Universitas Sebelas Maret Surakarta \\ ²ymuslih@yahoo.com \\ 3nikensilmisurjandari@gmail.com
}

\begin{abstract}
ABSTRAK
Pembangunan konstruksi di lokasi yang sempit dan lahan kerja yang terbatas seringkali menyebabkan galian struktur harus dilaksanakan secara tegak lurus, sehingga dibutuhkan dinding penahan untuk mengamankan galian agar tidak terjadi longsor. Bambu dipilih sebagai salah satu material kombinasi dinding penahan galian sementara karena memiliki sifat-sifat mekanika yang baik dan relatif murah. Penelitian ini bertujuan memperoleh informasi keamanan dan kelayakan bambu petung sebagai material konstruksi dinding penahan galian pada kondisi tanah non kohesif, pada konstruksi dinding penahan galian tanah dengan menggunakan kombinasi baja IWF dan bambu petung, sebagai alternatif desain dinding penahan tanah bagi pelaksana pekerjaan. Data yang diambil adalah data sekunder tanah non kohesif. Analisis data yang dilakukan meliputi analisis pembebanan, analisis tekanan tanah pada dinding penahan, dan analisis dimensi bambu (check kekuatan bahan). Hasil analisis menunjukkan bahwa material bambu petung layak dan aman digunakan sebagai alternatif material konstruksi dinding penahan galian pada kondisi tanah non kohesif. Diharapkan hasil penelitian ini dapat menjadi referensi bagi proyek-proyek yang memerlukan pelindung galian tegak.
\end{abstract}

Kata kunci: galian tegak, konstruksi dinding penahan tanah, kombinasi baja IWF dengan bambu

\section{PENDAHULUAN}

Dalam pembangunan suatu jalan raya, kondisi geografis dapat menyebabkan terjadinya titik-titik persimpangan sebidang, yang kemudian berkembang menjadi titik simpul sumber kemacetan. Salah satu solusi untuk mengurai kemacetan di persimpangan sebidang tersebut adalah adalah pembangunan jalan layang (flyover), agar persimpangan tersebut menjadi persimpangan tidak sebidang. Pelaksanaan pembangunan konstruksi jalan layang (fly over) seringkali terkendala masalah pembebasan lahan, yang menyebabkan pembongkaran bangunan di kanan dan kiri lokasi pembangunan jalan layang sulit dilaksanakan. Untuk mengerjakan struktur pilar pada pembangunan jalan layang ini harus menggunakan metode yang efisien dan aman, dengan memperhitungkan terbatasnya lahan, dikarenakan struktur pilar berada di tengah jalan raya. Padahal untuk metode pelaksanaan footing pilar dibutuhkan penggalian hingga kedalaman yang cukup dalam. Lalu lintas yang padat, lokasi yang sempit dan lahan kerja yang terbatas menyebabkan penggalian berbatasan langsung dengan jalan harus dilaksanakan secara tegak lurus, sehingga dibutuhkan dinding penahan untuk mengamankan galian agar tidak terjadi longsor.

Pada umumnya konstruksi dinding penahan galian tegak sementara menggunakan material steel sheet pile. Di sisi lain, proyek pembangunan jalan layang memerlukan penanganan yang cepat dengan biaya seefisien mungkin. Dalam makalah ini dikaji penggunaan material bambu petung (Dendrocalamus asper) dalam konstruksi kombinasi profil baja IWF dengan bambu petung sebagai alternatif desain dinding penahan galian tegak sementara. Alternatif konstruksi tersebut digunakan karena konstruksi tersebut relatif lebih murah dan material pembentuknya (profil baja IWF dan bambu) mudah didapatkan di pasaran bahan bangunan. Serta dalam pelaksanaannya 
menggunakan peralatan yang relatif lebih sederhana serta membutuhkan durasi pelaksanaan yang relatif lebih cepat.

Bambu petung (Dendrocalamus asper) dipilih sebagai salah satu material alternatif dinding penahan galian sementara untuk menahan longsor. Bambu memiliki sifat-sifat mekanika yang baik (Morisco, 1999) dan relatif murah dibanding material lain. Bambu juga dianggap cukup kuat sebagai pengganti tulangan baja pada balok beton ( Budi, et al., 2013). Kombinasi baja dengan bambu diduga cukup kuat untuk menahan galian tanah pada pembangunan pondasi pilar jalan layang. Namun belum pernah dijumpai penelitian mengenai penggunaan kombinasi baja IWF dan bambu petung sebagai dinding penahan galian pondasi pada proyek pembangunan jalan layang, sehingga diharapkan hasil penelitian ini dapat menjadi referensi bagi proyek pembangunan jalan layang ataupun pembangunan konstruksi lain yang membutuhkan pelindung galian tegak sementara.

\section{METODE PENELITIAN}

\section{Waktu dan lokasi penelitian}

Penelitian dilakukan pada antara bulan Maret sampai dengan bulan Juni tahun 2015. Semua asumsi beban tambahan di luar dinding penahan diambil dengan mengacu pada lokasi proyek Flyover Palur, Kabupaten Karanganyar, Jawa Tengah. Lokasi studi kasus dapat dilihat di Gambar 1.

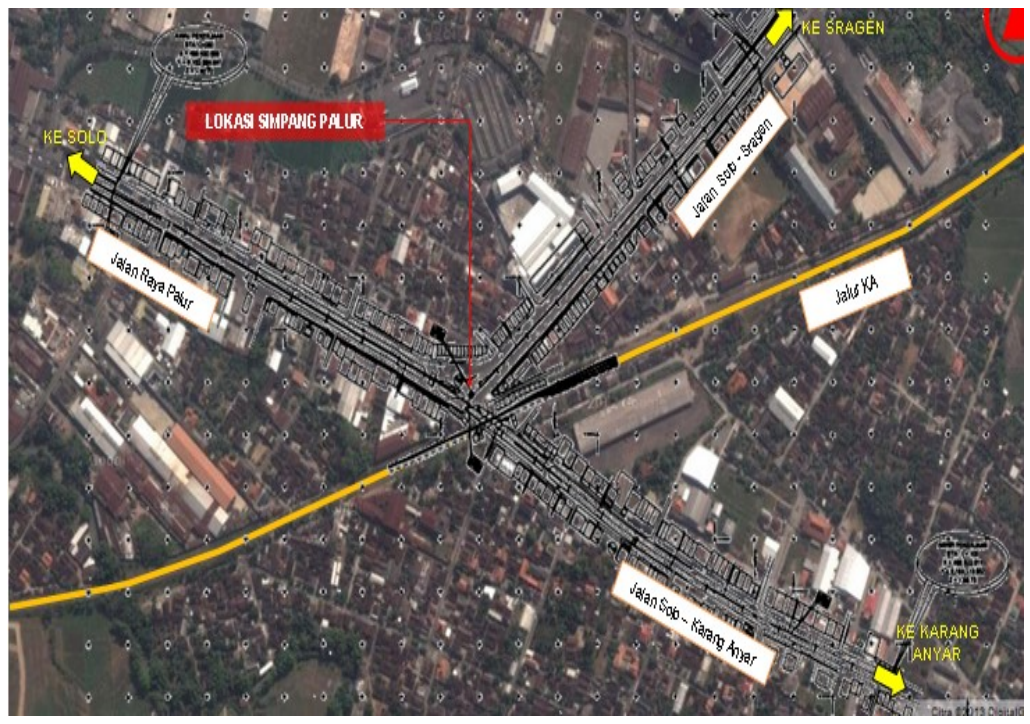

Gambar 1. Lokasi sampling (sumber : Google Earth)

\section{Pengumpulan data}

Dalam perencanaan desain dinding pelindung galian tegak ini diperlukan dua macam data, yakni data beban yang bekerja pada tanah pondasi diluar dinding turap (asumsi beban lalu lintas, alat berat dan mesin yang bekerja di samping galian) dan data parameter tanah (tanah non kohesif). Disamping itu juga diperlukan data properties bambu petung yang akan digunakan. Untuk data parameter tanah (tanah non kohesif) dan data properties bambu petung menggunakan data sekunder. 


\section{Analisis data}

Dalam penelitian ini dilakukan beberapa macam analisis, yaitu : 1) Analisis Beban tambahan di luar dinding penahan; 2) Analisis Tekanan Tanah Pada Dinding Penahan; 3) Analisis Properties Bambu Petung (check tegangan). Dalam makalah ini dibatasi hanya menganalisis sampai dengan kekuatan (keamanan) dan kelayakan material bambu untuk menahan tegangan yang terjadi sebagai alternatif material dinding penahan galian.

Analisis data pembebanan yang bekerja pada tanah pondasi diluar dinding turap diperkirakan sebesar $1 \mathrm{t} / \mathrm{m}^{2}$ (asumsi beban lalu lintas, alat berat dan mesin yang bekerja di samping galian sesuai kondisi pelaksanaan proyek Flyover Palur). Sedangkan analisis data tanah menggunakan metode perhitungan cara Rankine.

Dalam penelitian ini, analisis kekuatan bahan dari material bambu petung menggunakan desain dinding penahan galian dengan kombinasi baja IWF dan Bambu Petung, dimana tiang profil baja IWF dipancang dengan jarak tertentu (menjadi variabel panjang bambu dengan jarak sampling : $1 \mathrm{~m} ; 1,5 \mathrm{~m} ; 2 \mathrm{~m}$ ) dan dengan kedalaman sesuai desain (menjadi variabel dengan kedalaman galian sampling : $2 \mathrm{~m} ; 3 \mathrm{~m} ; 4 \mathrm{~m} ; 5 \mathrm{~m} ; 6 \mathrm{~m} ; 7 \mathrm{~m} ; 8 \mathrm{~m}$ ). Di antara tiang profil baja tersebut disisipkan bambu petung dengan diameter lebih kurang $15 \mathrm{~cm}$ dan tebal $1 \mathrm{~cm}$, yang disusun secara melintang dari bawah ke atas. Pada bagian atas dinding penahan dipasang perkuatan berupa walling beam dari baja IWF. Dan walling beam tersebut akan ditopang oleh profil baja penopang. Diasumsikan peletakan bambu pada profil baja merupakan peletakan sendi-sendi..

\section{Bagan alir}

Dengan mengacu desain dinding penahan galian, dilakukan proses analisa sesuai bagan alir pada Gambar 2.

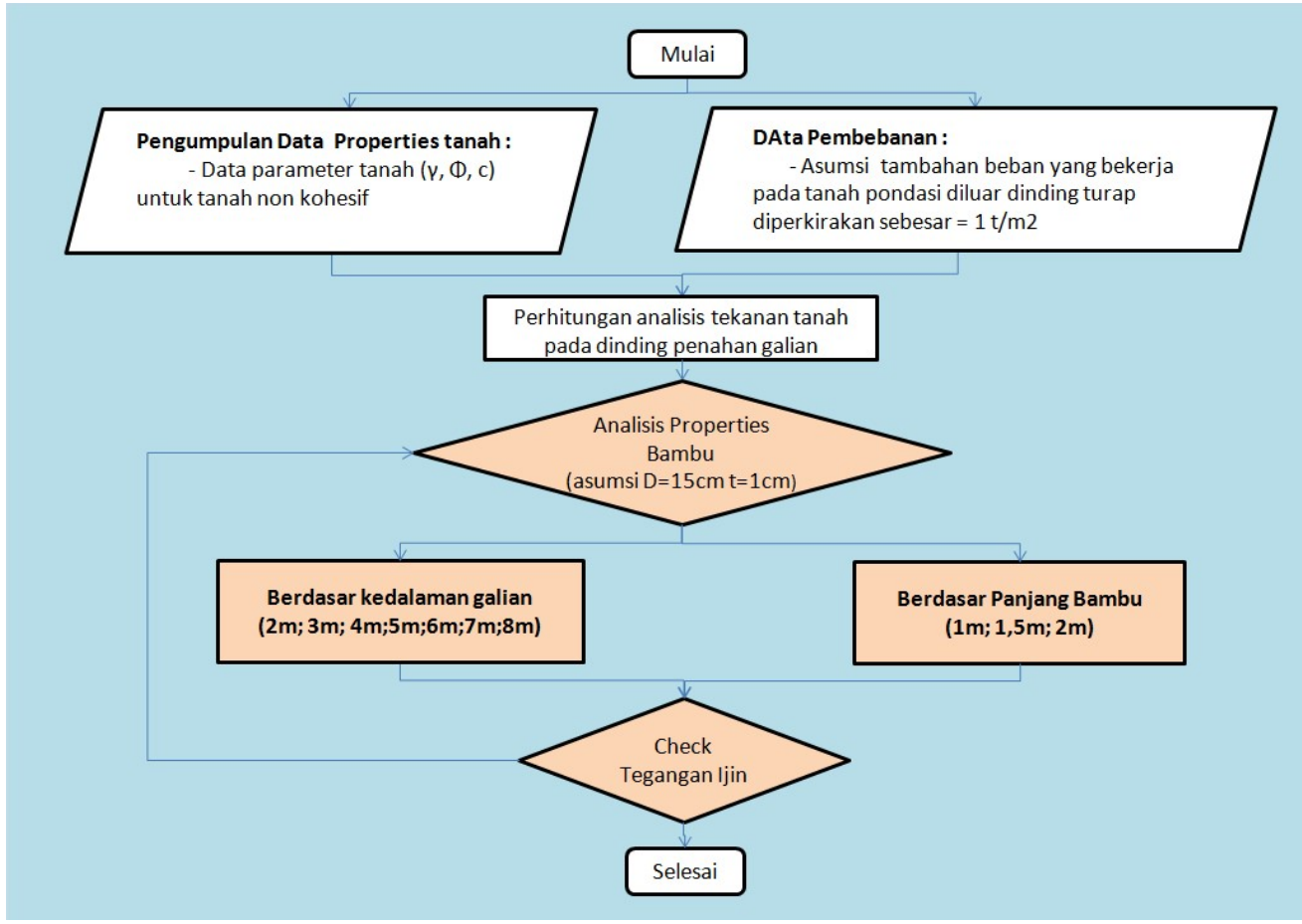

Gambar 2. Bagan alir 


\section{HASIL DAN PEMBAHASAN}

Data tambahan beban-beban yang bekerja pada tanah pondasi diluar dinding turap diperkirakan sebesar $=1 \mathrm{t} / \mathrm{m}^{2}$ (Asumsi beban lalu lintas, alat berat dan mesin yang bekerja di samping galian, mengacu pada kondisi di proyek Flyover Palur). Untuk data tanah dibuat variabel dengan parameter properties rata-rata untuk jenis tanah non kohesif (diambil parameter rata-rata untuk pasir lepas). Untuk mendapatkan parameter properties rata-rata dari jenis tanah non kohesif, mengacu dari hasil penelitian ataupun referensi pustaka yang telah ada, antara lain :

a. Data tekanan conus (qc) dan hambaan pelekat ( fs ) yang didapatkan dari tabel klarifikasi tanah dari data sondir (Tabel 1).

Tabel 1.Klasifikasi tanah dari data sondir

\begin{tabular}{|c|c|c|}
\hline \multicolumn{2}{|c|}{ Hasil sondir } & \multirow[t]{2}{*}{ Klasifikasi } \\
\hline$q c$ & $f s$ & \\
\hline 6,0 & $0,15-0,40$ & Humus, lempung sangat lunak \\
\hline \multirow{2}{*}{$6,0-10,0$} & 0,20 & Pasir kelanauan, pasir sangat lepas \\
\hline & $0,20-0,60$ & Lempung lembek, lempung kelanauan lembek \\
\hline \multirow{4}{*}{$10,0-30,0$} & 0,10 & Kerikil lepas \\
\hline & $0,10-0,40$ & Pasir lepas \\
\hline & $0,40-0,80$ & Lempung atau lempung kelanauan \\
\hline & $0,80-2,00$ & Lempung agak kenyal \\
\hline \multirow{2}{*}{$30-60$} & 1,50 & Pasir kelanauan, pasir agak padat \\
\hline & $1,0-3,0$ & Lempung atau lempung kelanauan kenyal \\
\hline \multirow{3}{*}{$60-150$} & 1,0 & Kerikil kepasiran lepas \\
\hline & $1,0-3,0$ & $\begin{array}{l}\text { Pasir padat, pasir kelanauan atau lempung padat dan lempung } \\
\text { kelanauan }\end{array}$ \\
\hline & 3,0 & Lempung kekerikilan kenyal \\
\hline $60-150$ & $1,0-2,0$ & $\begin{array}{l}\text { Pasir padat, pasir kekerikilan, pasir kasar pasir, pasir kelanauan sangat } \\
\text { padat }\end{array}$ \\
\hline
\end{tabular}

(sumber : Das, 1998)

b. Hubungan antara kepadatan dengan relative density, nilaiN SPT, qc dan $\varnothing$ didapat dari tabel hubungan antara kepadatan, relative density, nilai N SPT, qc dan Ø (Tabel 2).

Tabel 2. Hubungan antara kepadatan, relative density, nilai N SPT, qc dan

\begin{tabular}{lcccc}
\hline \multirow{2}{*}{ Kepadatan } & Relatif & Nilai $\boldsymbol{N}$ & Tekanan & Sudut \\
\cline { 2 - 4 } & Density $(\mathbf{D r})$ & $\boldsymbol{S}$ & $\begin{array}{c}\text { Konus qc } \\
\left(\mathbf{k g} / \mathbf{c m}^{2}\right)\end{array}$ & Geser (Ø) \\
\hline Very loose (sangat lepas) & $<0,2$ & $<4$ & $<20$ & $<30$ \\
\hline Loose (lepas) & $0,2-0,4$ & $4-10$ & $20-40$ & $30-35$ \\
\hline Medium dense (agak kompak) & $0,4-0,6$ & $10-30$ & $40,0-120$ & $35-40$ \\
\hline Dense (kompak) & $0,6-0,8$ & $30-50$ & $120-200$ & $40-45$ \\
\hline Very dense (sangat kompak) & $0,8-1,0$ & $>50$ & $>200$ & $>45$ \\
\hline & (sumber : Mayerhof, 1965) & &
\end{tabular}

c. Untuk menentukan korelasi empiris antara nilai N-SPT dengan unconfined compressive strength dan berat jenis tanah jenuh ( $\gamma$ sat) untuk tanah kohesif didapat dari tabel korelasi empiris antara nilai N-SPT dengan unconfined compressive strength dan berat jenis tanah jenuh $\left(\gamma_{\text {sat }}\right)$ untuk tanah kohesif (Tabel 3). 
Tabel 3. Korelasi empiris antara nilai N-SPT dengan unconfined compressive strength dan berat jenis tanah jenuh ( $\gamma$ sat) untuk tanah kohesif

\begin{tabular}{cccc}
\hline $\begin{array}{c}\text { N SPT } \\
\text { (blows/ft) }\end{array}$ & Konsistensi & $\begin{array}{c}\boldsymbol{q}_{\boldsymbol{u}} \\
\text { (Unconfined }\end{array}$ & $\begin{array}{c}\gamma_{\text {sat }} \\
\boldsymbol{k N}_{\mathbf{m}} \boldsymbol{m}^{\mathbf{3}}\end{array}$ \\
\hline$<2$ & Very soft & $<0,25$ & $16-19$ \\
\hline $2-4$ & Soft & $0,25-0,50$ & $16-19$ \\
\hline $4-8$ & Medium & $0,50-1,00$ & $17-20$ \\
\hline $8-15$ & Stiff & $1,00-2,00$ & $19-22$ \\
\hline $15-30$ & Very stiff & $2,00-4,00$ & $19-22$ \\
\hline$>30$ & Hard & $>4,00$ & $19-22$
\end{tabular}

(sumber : Terzaghi \& Peck, 1974 dalam Lambe \& Whitman, 1969)

d. Data berat volume tanah didapat dari tabel nilai tipikal berat volume tanah (Tabel 4)

Tabel 4. Nilai tipikal berat volume tanah

\begin{tabular}{ccc}
\hline Jenis $\boldsymbol{T a n a h}$ & $\begin{array}{c}\gamma_{\text {sat }} \\
\left(\boldsymbol{k} \boldsymbol{N}_{\boldsymbol{m}^{\mathbf{3}}}\right)\end{array}$ & $\begin{array}{c}\gamma_{\text {dry }} \\
\left(\boldsymbol{k} \boldsymbol{N} / \boldsymbol{m}^{\mathbf{3}}\right)\end{array}$ \\
\hline Kerikil & $20-22$ & $15-17$ \\
\hline Pasir & $18-20$ & $13-16$ \\
\hline Lanau & $18-20$ & $14-18$ \\
\hline Lempung & $16-22$ & $14-21$ \\
\hline
\end{tabular}

(sumber : Budhu, 2000)

e. Untuk hubungan antara sudut geser dalam dan jenis tanah didapat dari tabel hubungan antara sudut geser dalam dengan jenis tanah (Tabel 5).

Tabel 5. Hubungan antara sudut geser dalam dengan jenis tanah

\begin{tabular}{lc}
\hline \multicolumn{1}{c}{ Jenis tanah } & Sudut geser dalam \\
\hline Kerikil kepasiran & $35-40$ \\
\hline Kerikil kerakal & $35-40$ \\
\hline Pasir padat & $35-40$ \\
\hline Pasir lepas & 30 \\
\hline Lempung kelanauan & $25-30$ \\
\hline Lempung kelanauan & $20-25$ \\
\hline
\end{tabular}

(sumber : Das, 1998).

f. Untuk data kekuatan tarik bambu didapat dari diagram tegangan-regangan bambu dan baja (Gambar 3) serta tabel hasil pengujian 3 spesies bambu, Gigantochloa apus Kurz, Gigantochloa Verticillata Munro, dan Dendrocalamus asper Backer (tabel 6). 


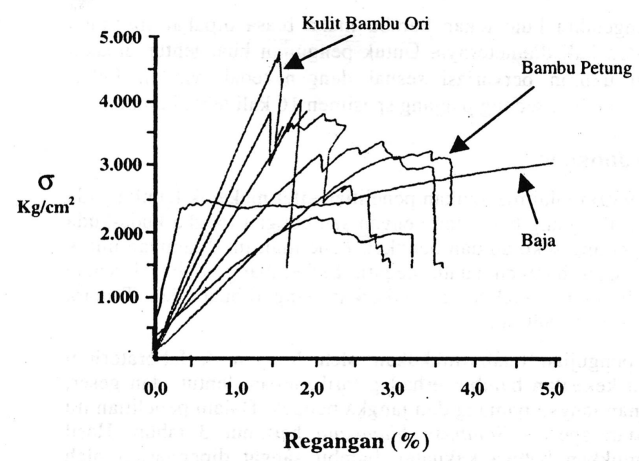

Gambar 3. Diagram tegangan-regangan bambu dan baja (sumber : Morisco, 1999)

Tabel 6. Hasil pengujian 3 spesies bambu, Gigantochloa apus Kurz, Gigantochloa Verticillata Munro, dan Dendrocalamus asper Backer

\begin{tabular}{ccc}
\hline Sifat & Kisaran & Jumlah Spesimen \\
\hline Kuat tarik & $1180-2750 \mathrm{Kg} / \mathrm{cm}^{2}$ & 234 \\
\hline Kuat lentur & $785-1960 \mathrm{Kg} / \mathrm{cm}^{2}$ & 234 \\
\hline Kuat tekan & $499-588 \mathrm{Kg} / \mathrm{cm}^{2}$ & 234 \\
\hline E tarik & $87280-313810 \mathrm{Kg} / \mathrm{cm}^{2}$ & 54 \\
\hline E tekan & $55900-211820 \mathrm{Kg} / \mathrm{cm}^{2}$ & 234 \\
\hline Batas regangan tarik & $0,0037-0,0244$ & 54 \\
\hline Berat jenis & $0,67-0,72$ & 132 \\
\hline Kadar lengas & $10,04-10,81 \%$ & 117 \\
\hline
\end{tabular}

(sumber : Siopongco dan Munandar, 1987 dalam Morisco, 1999)

Dari hasil beberapa penelitian dan pustaka yang ada, didapat tabel parameter data tanah non kohesif (tabel 7).

Tabel 7. Parameter Data Tanah Non Kohesif

\begin{tabular}{|c|c|c|c|c|c|c|c|c|c|}
\hline \multirow{2}{*}{$\begin{array}{l}\text { Jenis } \\
\text { Tanah }\end{array}$} & \multicolumn{3}{|c|}{ (Das, 1998) } & \multicolumn{3}{|c|}{ (Mayerhof,1965) } & \multicolumn{2}{|c|}{$\begin{array}{l}\text { Terzaghi \& } \\
\text { Peck,1974) }\end{array}$} & \multirow{2}{*}{$\begin{array}{c}\begin{array}{c}\text { (Budhu, } \\
2000)\end{array} \\
\begin{array}{c}\gamma_{s a t} \\
\mathrm{kN} / \mathrm{m}^{3}\end{array}\end{array}$} \\
\hline & $\begin{array}{c}q c \\
\mathrm{Kg} / \mathrm{cm}^{2}\end{array}$ & $\begin{array}{c}f s \\
\mathrm{Kg} / \mathrm{cm}^{2}\end{array}$ & $\varnothing$ & NSPT & $\varnothing$ & $D r$ & $\begin{array}{c}q u \\
T o n / f t^{2}\end{array}$ & $\begin{array}{c}\gamma_{\text {sat }} \\
\boldsymbol{k} \mathbf{N} / \mathrm{m}^{3}\end{array}$ & \\
\hline Kerikil & & & & & & & & & $20-22$ \\
\hline $\begin{array}{c}\text { Kerikil } \\
\text { Kepasiran }\end{array}$ & & & $35-40$ & & & & & & \\
\hline $\begin{array}{l}\text { Pasir } \\
\text { Padat }\end{array}$ & $60-150$ & $1-3$ & $35-40$ & $30-50$ & $40-45$ & $0,6-0,8$ & $>4$ & $19-22$ & \\
\hline $\begin{array}{l}\text { Pasir } \\
\text { Lepas }\end{array}$ & $10-30$ & $0,1-0,4$ & 30 & $4-10$ & $30-35$ & $0,2-0,4$ & $0,5-2$ & $17-22$ & $18-20$ \\
\hline
\end{tabular}

Dari tabel parameter data tanah non kohesif (tabel 7), sebagai acuan yang digunakan adalah kondisi pasir lepas, sehingga digunakan sudut geser $(\varnothing)=30$, $\gamma \mathrm{sat}=19,5 \mathrm{kN} / \mathrm{m}^{3}$ dan kohesi diabaikan $(\mathrm{c}=0)$.

Tolok ukur kuat lentur rata-rata bambu petung mengacu pada hasil pengujian yang disajikan pada (Tabel 6), yang merupakan hasil pengujian yang dilakukan Pusat Penelitian dan Pengembangan Pemukiman Departemen Pekerjaan Umum pada 3 spesies bambu yang umum di 
Indonesia, yakni bambu apus (Gigantochloa apus), bambu wulung (Gigantochloa verticillata) dan bambu petung (Dendrocalamus asper).

Menggunakan teori Rankine, berdasarkan data beban dan data parameter tanah non kohesif, dilakukan analisis tekanan tanah yang terjadi untuk masing-masing variabel kedalaman galian $(2 \mathrm{~m} ; 3 \mathrm{~m} ; 4 \mathrm{~m} ; 5 \mathrm{~m} ; 6 \mathrm{~m} ; 7 \mathrm{~m}$; dan $8 \mathrm{~m})$. Setelah diperoleh data tekanan tanah yang terjadi, tekanan tanah tersebut didistribusikan ke material bambu petung, untuk dianalisis tegangan yang terjadi akibat tekanan tanah tersebut dengan variabel panjang bambu. Adapun distribusi tegangan tanah dapat dilihat pada Gambar 4.

Dengan tambahan beban yang bekerja $(\mathrm{q})$ sebesar $=1 \mathrm{t} / \mathrm{m}^{2}$ (Asumsi beban mengacu pada kondisi proyek Flyover Palur), dan dengan variabel kedalaman galian, menggunakan teori Rankine dapat dihitung Koefisien Tanah Aktif (Ka) dan Tekanan Tanah Aktif akibat tanah di belakang dinding (Pa1) dan Tekanan Tanah Aktif akibat beban tambahan (Pa2).

$$
\begin{aligned}
& \mathrm{K}_{\mathrm{a}}=\operatorname{tg}^{2}\left(45^{0}-\frac{\phi}{2}\right) \\
& \mathrm{P}_{\mathrm{a} 1}=\left(\frac{1}{2} \cdot \gamma \cdot \mathrm{H}^{2}\right) \cdot \mathrm{K}_{\mathrm{a}}-2 \mathrm{c} \sqrt{\mathrm{K}_{\mathrm{a}}} \cdot \mathrm{H} \\
& \mathrm{P}_{\mathrm{a} 2}=(\mathrm{q} \cdot \mathrm{H}) \cdot \mathrm{K}_{\mathrm{a}}-2 \mathrm{c} \sqrt{\mathrm{K}_{\mathrm{a}}} \cdot \mathrm{H}
\end{aligned}
$$

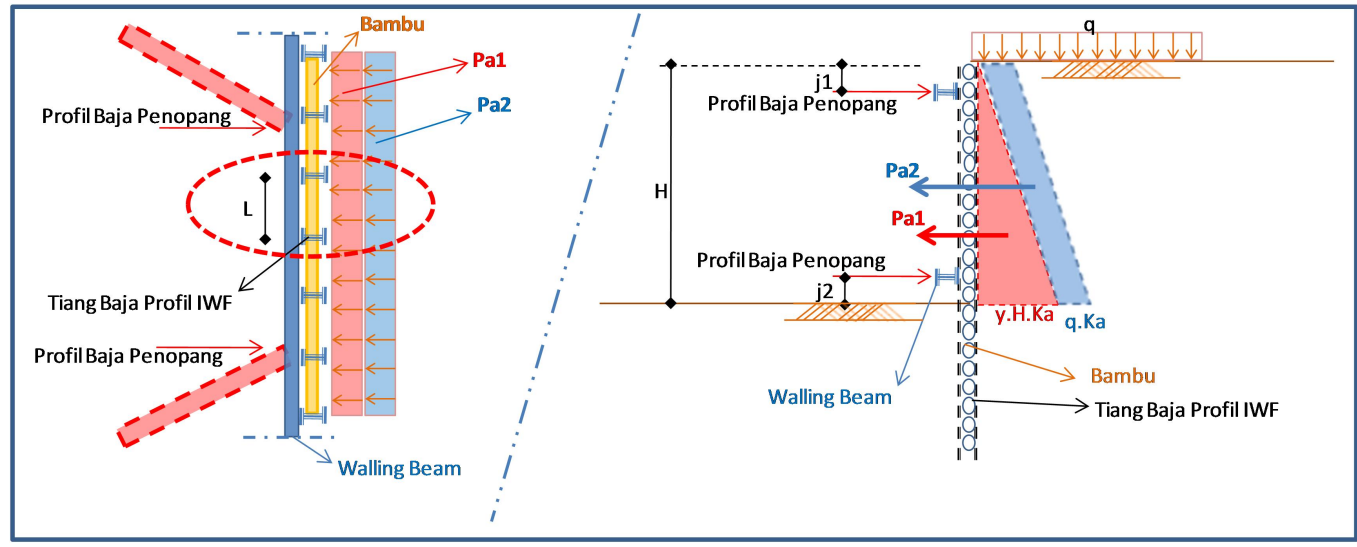

Gambar 4. Distribusi tegangan tanah

Detail distribusi tegangan tanah pada bambu disajikan pada Gambar 5.

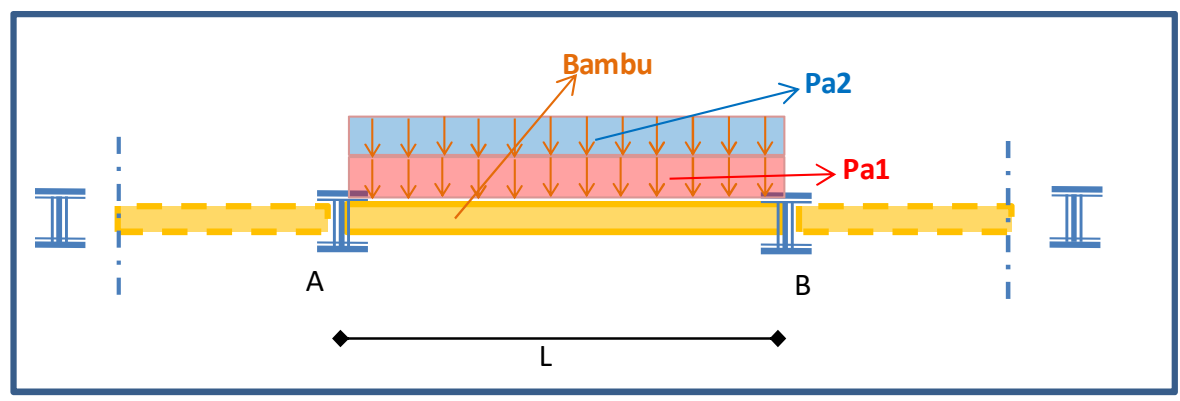

Gambar 5. Detail distribusi tegangan tanah pada bambu 
Dengan asumsi peletakan bambu pada tiang profil baja IWF merupakan peletakan sendi-sendi, dapat dicari besar momen maksimal yang dapat terjadi pada material bambu tersebut. Material bambu yang digunakan berdimensi diameter luar $(\mathrm{D}=15 \mathrm{~cm})$ dan diameter dalam $(\mathrm{d}=1 \mathrm{~cm})$. Dari data tersebut dapat dicari tegangan yang terjadi pada material bambu, dan dilakukan pengecekan terhadap tegangan lentur rata-rata untuk material bambu petung sebesar $785 \mathrm{~kg} / \mathrm{cm} 2$ (Siopongco dan Munandar, 1987 dalam Morisco, 1999).

Untuk mencari besar momen maksimal pada peletakan sendi-sendi menggunakan rumus :

$M_{n}=1 / 8\left(Q \cdot L^{2}\right)$

dimana Mn adalah besar momen maksimal, L merupakan panjang pias bambu (variabel), dan Q merupakan komulatif beban merata yang diterima bambu $(\mathrm{Q}=\mathrm{Pa} 1+\mathrm{Pa} 2)$.

Untuk mencari tegangan yang terjadi menggunakan rumus :

$\sigma=\frac{M_{n}}{W}=\frac{M_{n}}{\frac{\pi}{32}\left(\frac{D^{4}-d^{4}}{D}\right)}$

dimana $\sigma$ merupakan besaran tegangan yang terjadi, dan $\mathrm{W}$ merupakan momen lawan untuk material bambu.

Sebagai check keamanan konstruksi, dilakukan pengecekan terhadap tegangan lentur rata-rata untuk material bambu petung sebesar $785 \mathrm{~kg} / \mathrm{cm} 2$ (Siopongco dan Munandar, 1987 dalam Morisco, 1999).

Dari analisis tersebut diatas, akan didapat grafik hubungan kedalaman galian vs panjang bambu yang diijinkan untuk konstruksi dinding penahan galian di tanah non kohesif (pasir lepas), sebagaimana ditampilkan pada Gambar 6.

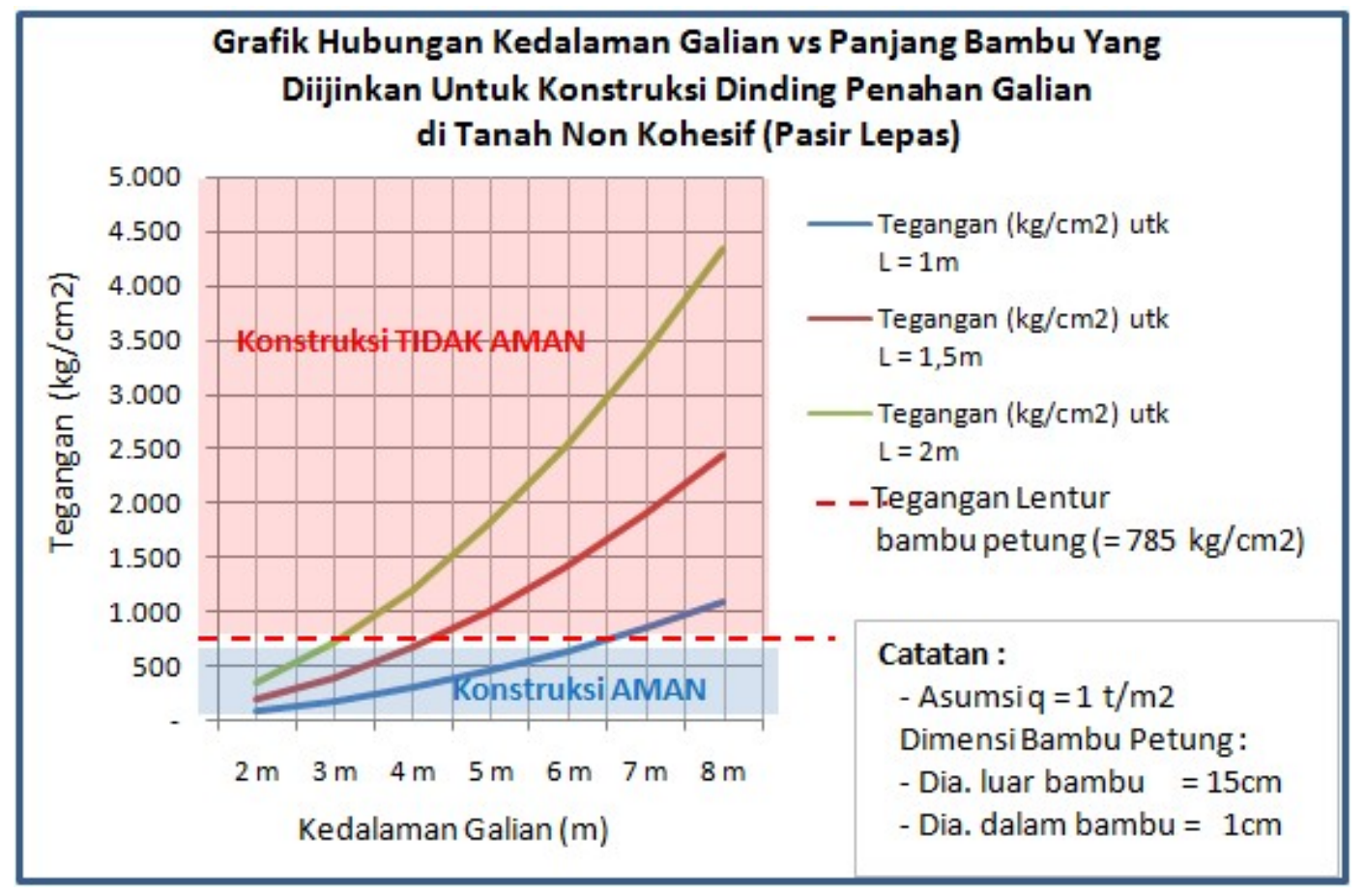

Gambar 6. Grafik hubungan kedalaman galian vs panjang bambu yang diijinkan untuk konstuksi dinding penahan galian di tanah non kohesif (pasir lepas) 
Berdasarkan grafik tersebut, asumsi kondisi beban tambahan (q) sebesar $1 \mathrm{t} / \mathrm{m}^{2}$ untuk lokasi dengan jenis tanah pasir non kohesif, dengan kajian keamanan ditinjau dari tegangan yang terjadi dibandingkan tegangan lentur bambu petung, dan menggunakan material bambu petung dengan diameter luar $(\mathrm{D}=15 \mathrm{~cm})$ dan diameter dalam $(\mathrm{d}=1 \mathrm{~cm})$, didapat bahwa :

g. Untuk panjang pias bambu (L) sebesar $1 \mathrm{~m}$, ditinjau dari segi tegangan yang terjadi, konstruksi masih aman untuk kedalaman galian sampai $6 \mathrm{~m}$.

h. Untuk panjang pias bambu (L) sebesar 1,5m, ditinjau dari segi tegangan yang terjadi, konstruksi masih aman untuk kedalaman galian sampai $4 \mathrm{~m}$.

i. Untuk panjang pias bambu (L) sebesar $2 \mathrm{~m}$, ditinjau dari segi tegangan yang terjadi, konstruksi masih aman untuk kedalaman galian sampai $3 \mathrm{~m}$.

\section{KESIMPULAN DAN SARAN}

Dari hasil analisis, ditinjau dari kemampuan menahan tegangan yang terjadi, didapatkan bahwa material bambu petung layak dan aman digunakan sebagai material alternatif konstruksi penahan galian pada tanah non kohesif, untuk kedalaman galian sampai dengan 6 meter. Diharapkan hasil analisis ini dapat bermanfaat bagi praktisi yang memerlukan alternatif desain guna menahan ancaman longsoran dari konstruksi galian tegak.

\section{Ucapan Terima Kasih (Acknowledgement)}

Akhir kata, saya mengucapkan terima kasih yang sebesar-besarnya kepada Tim Proyek Pembangunan Flyover Palur, dan kepada semua pihak yang tidak dapat disebutkan satu-persatu. Terima kasih.

\section{REFERENSI}

Budhu, M. 2000. Soil Mechanics and Foundations. John Willey \& Sons, NewYork.

Budi,A.S., Sambowo, K.A., and Kurniawati, I. 2013. Model Balok Beton Bertulangan Bambu Sebagai Pengganti Tulangan Baja. Prosiding Konferensi Nasional Teknik Sipil 7. Universitas Sebelas Maret. Surakarta.

Das, B. M. 1998. Mekanika Tanah : Prinsip-Prinsip Rekayasa Geoteknis Jilid 1 (Terjemahan). Erlangga, Jakarta.

Das, B. M., 1998. Mekanika Tanah : Prinsip-Prinsip Rekayasa Geoteknis Jilid 2 (Terjemahan), Erlangga, Jakarta.

Hardiyatmo, H.C. 2012. Mekanika Tanah 1. Gadjah Mada University Press, Yogyakarta.

Hardiyatmo, H.C. 2012. Mekanika Tanah 2. Gadjah Mada University Press, Yogyakarta.

Irsyam, M. 2012. Rekayasa Pondasi. Penerbit ITB. Bandung.

Lambe, T.C., dan Whitman, R. V. 1969. Soil Mechanics. John Wiley Sons, NewYork.

Mayerhof, G.G.1965. Shallow Foundation. Journal ASCE, Soil MechanicFoundation Div, vol. 91. No. SM2.

Morisco. 1999. Rekayasa Bambu. Penerbit Nafiri. Yogyakarta. 